\title{
Pathway control in the self-construction of complex precipitation forms in a $\mathrm{Cu}(\mathrm{II})$-oxalate system
}

Agota Toth², Dezso Horvath², Akos Kukovecz ${ }^{3}$, Maciej Maselko ${ }^{4}$, Anne Baker ${ }^{1}$, Shareen Ali ${ }^{1}$ and Jerzy Maselko ${ }^{{ }^{*}}$

\begin{abstract}
Text Abstract
Background: Many biological systems contain complex precipitation patterns. These structures are considered to be the result of finely tuned and genetically encoded developmental pathways. The amount of encoded information needed to generate and manipulate these structures is poorly understood. Investigating the dynamics of spontaneous pattern formation in non-biological systems provides insights to the physio-chemical phenomena that biological systems must have harnessed for living systems and that modern scientists need to understand for complex nano-technological applications.
\end{abstract}

Results: Here we show that highly complex, precipitation patterns similar to those found in biological systems can be formed in simple $\mathrm{Cu}(\mathrm{II})$-oxalate systems. In these $\mathrm{Cu}(\mathrm{II})$-oxalate systems, structures are constructed by a hierarchy of multiple processes that are precisely self-organized in space and time to form interconnected causal networks that generate complex and diverse structures dependent on construction trajectories that can be controlled by minor variations of initial conditions.

Conclusions: Highly complex precipitation patterns similar to those found in biological systems can be generated without a correspondingly complex set of instructions. Our result has implications for understanding early biotic systems that existed prior to the evolution of sophisticated genetic machinery. From an applications perspective, processes and structures that occur spontaneously are the building blocks for novel system chemistry based technologies where products are self-constructed. We also provide a simple model of chemical system that generates biomimetic structures for the study of fundamental processes involved in chemical self-construction.

Keywords: Precipitation patterns, Silicate garden, Self-construction

\section{Background}

The formation of complex precipitation structures in biological systems such as those found in diatoms, coccolithophorids, corals and seashell shave been the subject of intensive investigations [1-3]. Such precipitation structures are hierarchical, being constructed of many different substructures on nano, meso, micro and higher scales. Molecular biology is useful for understanding which genes are important for the generation of these structures, however, the physical and chemical processes that generate complex structures must also be studied in order to understand how

\footnotetext{
* Correspondence: jmaselko2@uaa.alaska.edu

'Department of Chemistry, University of Alaska, Anchorage, AK 99508, USA Full list of author information is available at the end of the article
}

biological systems evolved to manipulate them as well as for technological applications. Until recently, most chemistry-centered studies have focused on elucidating the chemical compositions of structures' subunit crystals and methods for controlling crystal morphologies [3-5]. Here we show that highly complex precipitation structures can be formed in very simple $\mathrm{Cu}$ (II)-oxalate systems. Our results suggest that the formation of many highly complex structures seen in nature may occur by nucleating and regulating spontaneous construction processes.

Complex precipitation patterns are naturally found in both biological and non-biological systems. Biological precipitation patterns are precisely organized and are the products of multiple processes which, despite some progress made in the field of pattern
(C) Chemistry Central

C 2012 Toth et al.; licensee Chemistry Central Ltd. This is an Open Access article distributed under the terms of the Creative Commons Attribution License (http://creativecommons.org/licenses/by/2.0), which permits unrestricted use, distribution, and reproduction in any medium, provided the original work is properly cited. 
formations and in self-assembly [6-10], are still beyond the technical capabilities of modern chemists. In contrast, complex non-biological precipitation formations such as stalagmites and stalactites [11], Liesegang Rings [12], geological structures [13], snowflakes and Silicate Gardens [14-22] have been synthesized in vitro. These structures may share some similarities to biological structures and are considered important in the study of the origin of life [23,24]. However, these non-biological structures are usually the products of one process and one "building element" such as the crystallization of water molecules in the formation of snowflakes. The $\mathrm{Cu}(\mathrm{II})$-oxalate systems we describe are more similar to the biological precipitation formations with multiple different "building blocks" and numerous processes that are precisely organized in space and time yet form spontaneously.

Systems Chemistry [25-27], similar to Systems Biology is concentrated mostly on the structures and properties of complex systems. Our understanding of how such systems can emerge is less developed and a general theory of self-construction does not yet exist. In this study we concentrate almost exclusively on how complex structures construct themselves.

\section{Results and discussion}

In the present system, a pellet of copper sulfate was immersed in solutions with different concentrations of oxalate and the processes that lead to complex structures were observed. In each case, the copper dissolved into the surrounding solution [18]. Due to density differences, the more concentrated solution sinks to the bottom of the reaction dish and spreads across it to form a layer on the bottom. The bottom solution then moves outward from the pellet, while the upper solution moves towards the pellet.

At an oxalate concentration of $0.02 \mathrm{M}$ during the movement of solutions, copper oxalate is formed and makes a thin finger-like precipitation pattern. At $0.05 \mathrm{M}$ sodium oxalate, in addition to the fingers, a light blue disc-like structure made of $\mathrm{CuC}_{2} \mathrm{O}_{4}$ with a diameter of about $3 \mathrm{~cm}$ develops on the bottom of the dish (Figure 1A). When the oxalate concentrations increased above $0.05 \mathrm{M}$ the disk becomes more pronounced and reaches $1 \mathrm{~mm}$ in thickness. At $0.11 \mathrm{M}$ oxalate a dark blue crystalline "urchin" structure not observed at lower oxalate concentrations forms while the thin fingers are absent (Figure 1B \& C). The dark blue crystal growth begins from many initiation points all around the disc and radiates in all directions. Chemical analysis
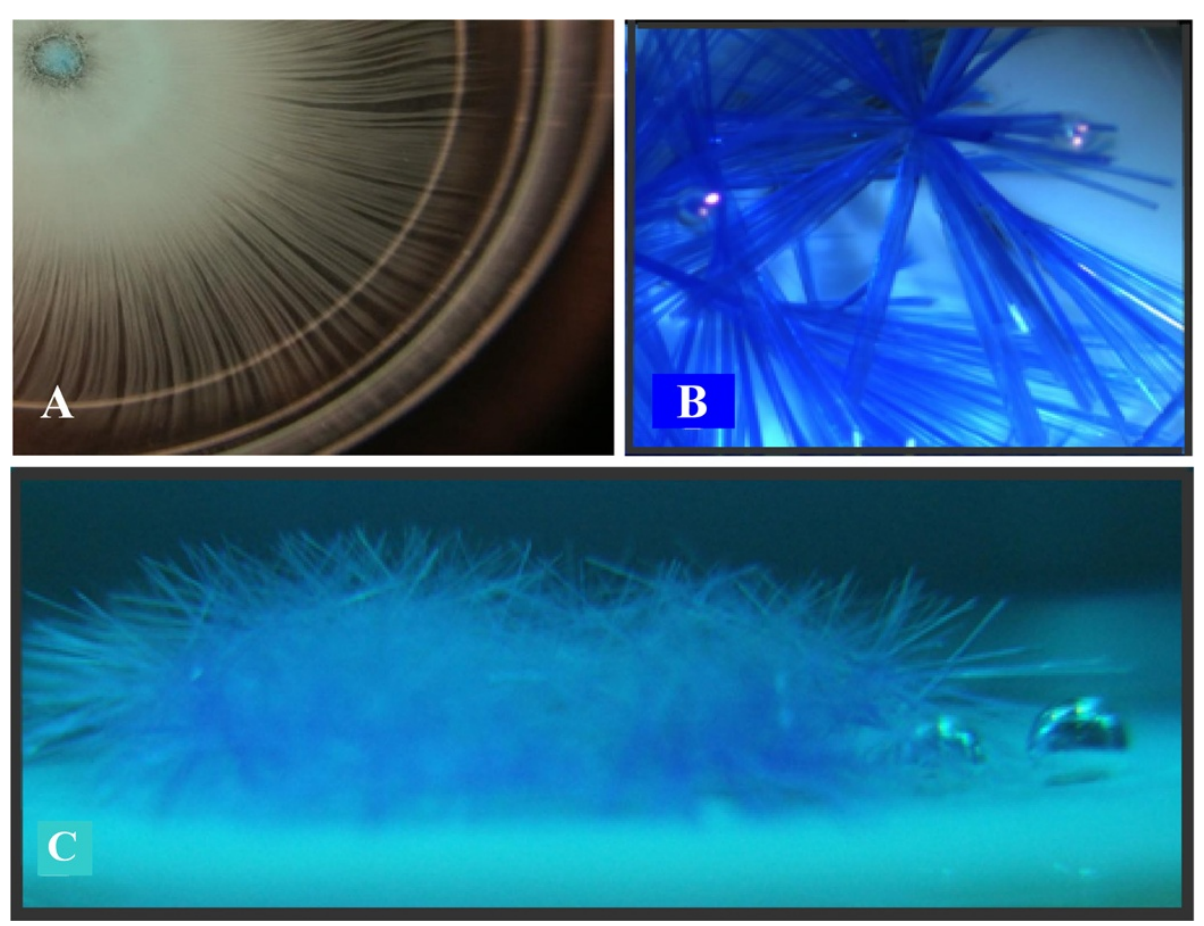

Figure 1 Complex precipitation structures: a Fingers with a precipitation disc, concentration of oxalate $0.05 \mathrm{M}$. On the left upper corner the pellet is visible (20 min after beginning of experiments). $\mathbf{B}$ Top view of a precipitation disk $\left(\mathrm{CuC}_{2} \mathrm{O}_{4}\right)$ with crystals on top, oxalate concentration $0.11 \mathrm{M} 24 \mathrm{~h}$. C Side view of this structure. The formation of the disk occurs in $20 \mathrm{~min}$. The disk diameter is about $3.0 \mathrm{~cm}$. The picture was taken after $24 \mathrm{~h}$. 
confirms that these dark blue crystals are made from $\mathrm{Na}_{2} \mathrm{Cu}\left(\mathrm{C}_{2} \mathrm{O}_{4}\right)_{2} \times 2 \mathrm{H}_{2} \mathrm{O}$.

The light blue crystals which are the subunits of the thin fingers (Figure 1A) and light blue disk (Figure 1A $\& B)$ are formed by the following reaction:

$$
\mathrm{Cu}^{2+}+\mathrm{C}_{2} \mathrm{O}_{4}{ }^{2-}=\mathrm{CuC}_{2} \mathrm{O}_{4(\mathrm{~s}) .} \mathrm{K}_{\mathrm{sp}}=4.4 \times 10^{-10}
$$

In our system, at oxalate concentrations above $0.11 \mathrm{M}$, the $\mathrm{CuC}_{2} \mathrm{O}_{4(\mathrm{~s})}$ undergoes dissolution according to following reaction:

$$
\mathrm{CuC}_{2} \mathrm{O}_{4(\mathrm{~s})}+\mathrm{C}_{2} \mathrm{O}_{4}{ }^{2-}=\mathrm{Cu}\left(\mathrm{C}_{2} \mathrm{O}_{4}\right)_{2}{ }^{2-} \cdot \mathrm{K}_{\mathrm{sp}}=10^{7.6}
$$

This reaction provides a necessary reactant for the formation of the dark blue $\mathrm{Na}_{2} \mathrm{Cu}\left(\mathrm{C}_{2} \mathrm{O}_{4}\right)_{2} \times 2 \mathrm{H}_{2} \mathrm{O}$ crystals (Figure $1 \mathrm{~B} \& 1 \mathrm{C}$ ) according to the following equation:

$$
\begin{gathered}
2 \mathrm{Na}^{+}+\mathrm{Cu}\left(\mathrm{C}_{2} \mathrm{O}_{4}\right)_{2}{ }^{2-}+2 \mathrm{H}_{2} \mathrm{O} \\
=\mathrm{Na}_{2} \mathrm{Cu}\left(\mathrm{C}_{2} \mathrm{O}_{4}\right)_{2} \times 2 \mathrm{H}_{2} \mathrm{O}_{(\mathrm{s})}
\end{gathered}
$$

The precipitation patterns are substantially more complicated for $0.15-0.25 \mathrm{M}$ oxalate as presented in Figure 2. Initially, a $\mathrm{CuC}_{2} \mathrm{O}_{4(\mathrm{~s})}$ precipitation disk forms. At the edge of this disk $\mathrm{Na}_{2} \mathrm{Cu}\left(\mathrm{C}_{2} \mathrm{O}_{4}\right)_{2} \times 2 \mathrm{H}_{2} \mathrm{O}_{(\mathrm{s})}$ structures very distinct from the dark blue crystals seen at $0.11 \mathrm{M}$ oxalate (Figure 1B \& $1 \mathrm{C}$ ) form from a handful of initiation points (Figure 2A). Crystalline projections "fans" from these initiation points grow towards the center of the disk and eventually cover its entire surface (Figure $2 \mathrm{~B} \& 2 \mathrm{C}$ ). During a period of approximately 10 hours, the $\mathrm{CuC}_{2} \mathrm{O}_{4(\mathrm{~s})}$ disk disappears altogether through transformation to the structure shown in Figure 2D. The volume of this structure increases by a factor of 10 in comparison with the structure presented on Figure 2A \& B and the height changes from $2 \mathrm{~mm}$ to $20 \mathrm{~mm}$. The stem of this "mushroom" structure is filled with a gel-like substance. The gel was removed from the solution, washed, and dried for analysis which determined that the composition is $\mathrm{Na}_{2} \mathrm{Cu}$ $\left(\mathrm{C}_{2} \mathrm{O}_{4}\right)_{2} \times \mathrm{O}_{2} \mathrm{H}_{2} \mathrm{O}$.

We also investigated the microscopic structure of the precipitation patterns and found that each was constructed from a morphologically distinct crystal subunit (Figure 3A-D). The $\mathrm{CuC}_{2} \mathrm{O}_{4}$ crystals forming the light blue fingers (Figure 1A) are constructed from filaments (Figure 3A) and the $\mathrm{CuC}_{2} \mathrm{O}_{4}$ precipitation disk is constructed from intricate spherical subunits (Figure $3 \mathrm{~B}$ ). The dark blue $\mathrm{Na}_{2} \mathrm{Cu}\left(\mathrm{C}_{2} \mathrm{O}_{4}\right)_{2} \times 2 \mathrm{H}_{2} \mathrm{O}$ crystal (Figure $1 \mathrm{~B}$ $\& 1 \mathrm{C})$ subunits are seen in (Figure $3 \mathrm{C}$ ). The fans (Figure 2B \& 2C) are composed of other unique crystal structures (Figure 3D). Their formation is presumably controlled by system hydrodynamics where local
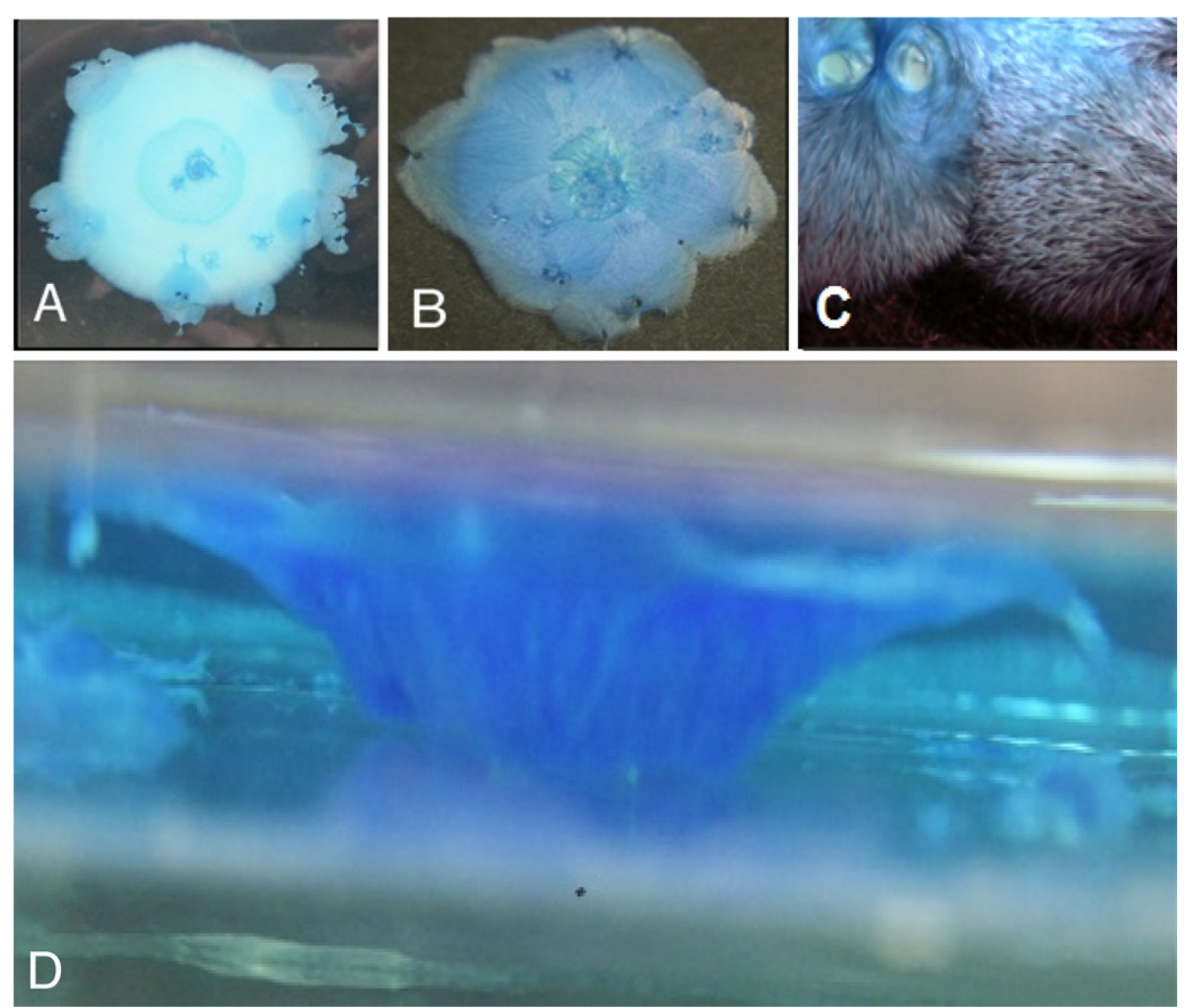

Figure 2 Complex precipitation structure at $0.15-0.25 \mathrm{M}$ sodium oxalate concentration: a Fans forming at the edge of the disk with a diameter of $3 \mathrm{~cm},(10 \mathrm{~min})$ B "Fans" covering the entire disk, ( $2 \mathrm{~h}), \mathrm{C}$ Magnification of the fans, D "Mushroom" structure formed after 24 hours. The dark blue pillars supporting structure are visible. 

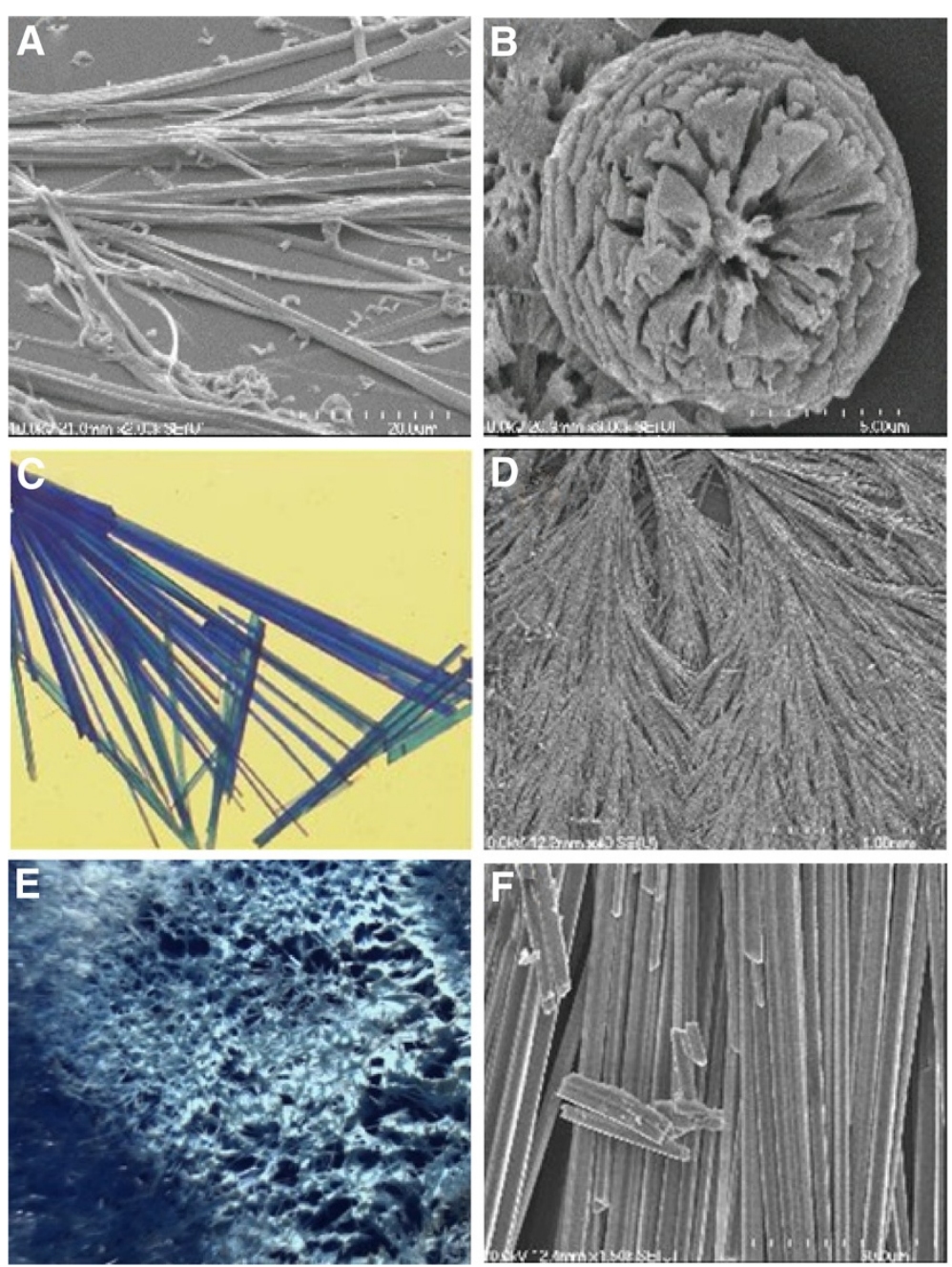

Figure 3 Images of crystals: a SEM images of crystals constituting the fingers, the width of the picture corresponds to $64 \mu \mathrm{m}$. B SEM image of crystals forming the precipitation ring, the size of the picture correspond to $14,2 \mu \mathrm{m}$. C Crystals from Figure 1C, D. D Structure from "fans" Figure 2A, C. E Structure obtained after drying "mushroom" from Figure 2D, with $1.0 \mathrm{~cm}$. F Crystals after drying mushroom, SEM image, width of picture correspond to $85,3 \mu \mathrm{m}$.

changes in oxalate concentrations are causing changes in solution density and viscosity. Formation of the mushroom morphology is more complex. In the microscopic picture shown on (Figure 3E), one can see hollows that develop from the drying of the gel. The formed crystals are presented on (Figure 3F).

As is the case in biological systems, the formation of these complex structures involves many processes. Physical processes include the diffusion of copper ions from the pellet to the oxalate solution, establishment of a density gradient resulting in the solute convection of concentrated solution downwards and away from the pellet across the bottom of the dish while less dense solution moves toward the pellet. Chemical processes include $\mathrm{CuSO}_{4}$ dissolution, formation of $\mathrm{CuC}_{2} \mathrm{O}_{4}$ crystals with two different morphologies, formation of crystals of $\mathrm{Na}_{2} \mathrm{Cu}\left(\mathrm{C}_{2} \mathrm{O}_{4}\right)_{2} \times 2 \mathrm{H}_{2} \mathrm{O}$ with two different morphologies and a gel. The $\mathrm{CuC}_{2} \mathrm{O}_{4(\mathrm{~s})}$ precipitation disk serves to organize crystal growth. For oxalate concentrations in the range of $0.15-0.25 \mathrm{M}$, we observe metamorphosis i.e., the transition of one form into another (see Figure 2B, 2D). Usually, in hierarchical constructions, one structure is built from others. In the presented experiments, however, there is a full metamorphosis to a different structure without elements of the first structure remaining.

In our experiments, the initial conditions have a "seed" arrangement which is somewhat analogous to biological morphogenesis. In this experiment, the copper sulfate "seed" is surrounded by an environment of sodium oxalate. This non-homogeneous arrangement establishes various potential gradients that define a network of chemical and physical processes. This network and its oxalate concentration dependent bifurcation points, 


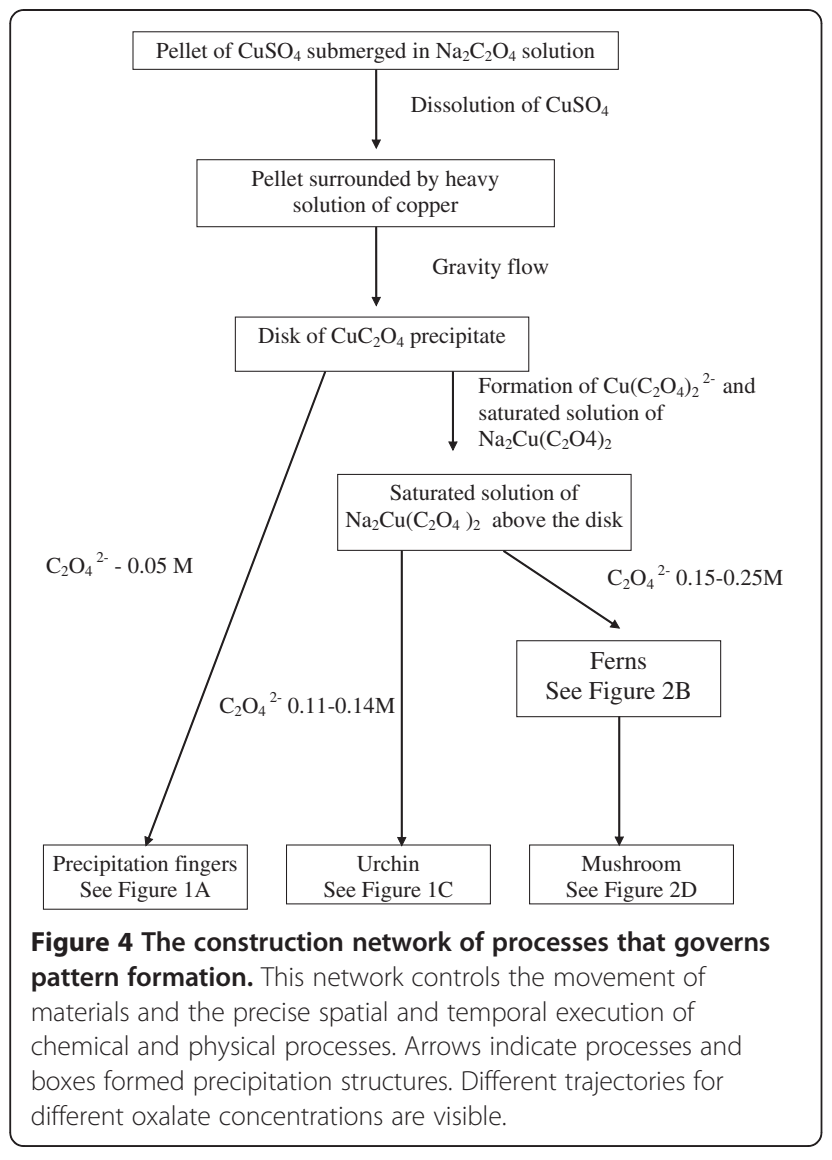

shown in a schematic diagram (Figure 4), controls the precise spatio-temporal execution of chemical and physical processes which lead to the construction of complex precipitation patterns. The initially formed chemical structures establish subsequent potential differences and a cascade of processes develops. Small changes to system parameters (i.e. initial oxalate concentration) leads to switching the construction trajectory from one pathway in the processes network to another, leading to a radically different structure therefore we can control the system trajectory and which structures are formed.

The sophistication of processes and complexity of structures that are generated by this simple system has ramifications for our understanding of primitive life and evolutionary processes. Some complex structures do not need to have evolved in a slow, step by step fashion and could exist in the absence of large amounts of genetic

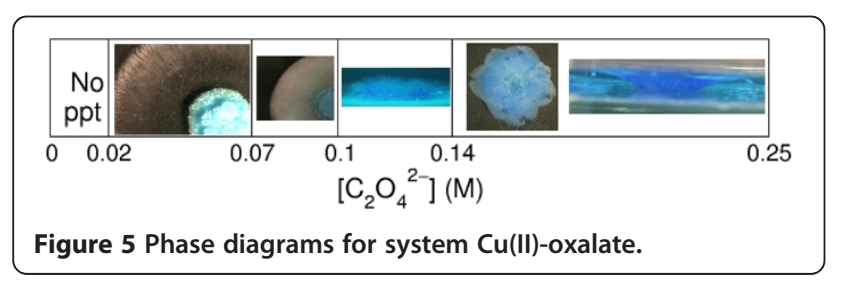

information if organisms could nucleate spontaneous, complex processes. Small changes in genes that control nucleation conditions could also lead to drastic new structural forms.

\section{Conclusions}

We have shown that highly complex, precipitation patterns similar to those found in biological systems can be formed in the $\mathrm{Cu}(\mathrm{II})$-oxalate reaction (see Figure 5). This simple system presents an excellent model for investigating the principles of self-construction. Future enquires will explore the construction of more complex networks of chemical and physical processes and investigate their control via catalysts and inhibitors as seen in biological systems. Ultimately, further understanding of selfconstruction will enable us to comprehend the formation of complex structures in biology and develop technologies that lead to sophisticated self-constructed materials.

Understanding and mastering the process of formation of complex structures in chemical systems will lead to an understanding of formation of complex structures in nature. Mastering processes of controlling of networks of chemical processes will lead to new technologies, applied especially on the nano level, where the process of piece by piece assembly is not possible.

\section{Experimental}

A $1.0 \mathrm{~g}$ pellet of copper sulfate (VWR) was prepared by grinding copper sulfate crystals in an electric grinder for 5 minutes and then casting it into a pellet using a pellet maker commonly utilized in IR studies. Each pellet was standardized to $1.0 \mathrm{~cm}$ in diameter and $4 \mathrm{~mm}$ in height. A $22 \mathrm{~cm}$ diameter Petri dish was leveled and sodium oxalate was poured into the dish. Pellets were then placed into the center of the reaction dish. Concentration of oxalate (VWR) was varied between 0.0 to $0.25 \mathrm{M}$. To determine the crystal composition, the copper contents were analyzed spectrophotometrically after dissolving crystals in a solution of ammonia. The oxalate concentration was determined by titration with permanganate after dissolving the crystals in sulfuric acid. The experiments were carried out at a temperature of $20 \pm 1^{\circ} \mathrm{C}$. Scanning electron microscope images were taken of the dried precipitate by a Hitachi S-4700 high-resolution scanning electron microscope.

\section{Competing interests}

The authors declare that they have no competing interests.

\section{Authors' contributions}

AT, DH, JM designed the experiments, made data interpretation and wrote the manuscript, $A K$ performed microscope study, $A B, S A$, undergraduate students at UAA, performed experiments, MM provided intellectual input on these experiments concerning relation to biological systems and wrote the manuscript. All authors have read and approved the final manuscript. 


\section{Acknowledgements}

This work was supported by the National Science Foundation (Grant No. CHE-0608631 and CHE-1011656).

We would like to thank our undergraduate students, from the University of Alaska Anchorage, that have conducted preliminary experiments: Leon RoseFigura, Ester Heo, Sheila Elano, Ashley Holombo.

\section{Author details}

'Department of Chemistry, University of Alaska, Anchorage, AK 99508, USA. ${ }^{2}$ Department of Physical Chemistry and Materials Science, University of Szeged, H-6720, Szeged, Hungary. ${ }^{3}$ Department of Applied and Environmental Chemistry, University of Szeged, H-6720, Szeged, Hungary. ${ }^{4}$ Molecular and Cellular Biology Program, Oregon State University, Corvallis, Oregon 97331, USA.

Received: 4 April 2012 Accepted: 17 July 2012

Published: 2 August 2012

\section{References}

1. Thompson DW: On Growth and Form. Cambridge: Cambridge University Press; 1942.

2. Fontana W: Algorithmic chemistry. In Artificial Life II. Edited by Langton CG, Taylor C, Farmer JD, Rasmussen S.: Reading:Addison-Wesley; 1992:159-210.

3. St. Mann Biomineralization. Oxford: Oxford University Press; 2001

4. Meldrum FC, Colfen $\mathrm{H}$ : Controlling mineral morphologies and structures in biological and synthetic systems. Chem Rev 2008, 108:4332-4432.

5. Hildebrand M: Diatoms, Biomineralization Processes, and Genomics. Chem Rev 2008, 108:4855-4874.

6. Gordon LM, Joester D: Nanoscale chemical tomography of buried organic-inorganic interfaces in the chiton tooth. Nature 2011, 468:194-197.

7. Ir E, Pojman J: An Introduction to Nonlinear Dynamics, Oscillations, Waves, Patterns, and Chaos. Oxford: Oxford Univ. Press; 1998.

8. Whitesides GM, Grzybowski B: Self-assembly at all scales. Science 2002, 295:2418-2421.

9. Desai RC, Kapral R: Dynamics of Self-Organized and Self-Assembled Structures Cambridge: Cambridge Univ. Press; 2009.

10. Maune HT, Han S-P, Barish RD, Bockrath M, William A, Goddard III, Rothemund PWK, Winfree E: Self-assembly of carbon nanotubes into twodimensional geometries using DNA origami templates. Nat Nanotechnol 2010, 5:61-66.

11. Hill C, Forti P: Cave Minerals of the World. Huntsville Al: Natl. Speleol. Soc; 1997.

12. Stern KH: A Bibliography of Liesegang Rings. 2nd edition. Washington: U.S Government Printing Office; 1967.

13. Chadam J, Ortoleva P, Sen A: A weakly nonlinear stability analysis of the reactive infiltration interface. SIAM J Appl Math 1988, 48:1362.

14. S.T. Leduc: The mechanism of life. New York: Rebman: New York; 1911.

15. Collins C, Zhou W, Mackay A, Kalinowski J: Studies of the growth of "silicate garden" and related phenomena. Chem Phys Lett 1998, 286:88-92.

16. Coatman RD, Thomas NL, Double D: The 'Silica garden' a hierarchical structure. J Mater Sci 2002, 15:2017-2022.

17. Cartwright JH, Garcia-Ruiz JM, Novella ML, Otarola F: Formation of Chemical Garden. J Colloid Interface Sci 2002, 256:351-359.

18. Smith R, McMahan JR, Braden J, Mathews E, Toth A, Horvath D, Maselko J: Phase diagram of precipitation morphologies in the $\mathrm{Cu}^{2+}-\mathrm{PO}_{4}^{3-}$ system. J Phys Chem C 2007, 111:14762-14767.

19. Thouvenel-Romans S, Steinbock O: Oscillatory growth of silica tubes in chemical garden. J Am Chem Soc 2003, 125:4338-4341.

20. Ritchie C, Cooper G, Song Y-F, Streb C, Yin H, Parenty A, McLaren D, Cronin $\mathrm{L}$ : Spontaneous assembly and real-time growth of micron-scale tubullar structures from plolyoxometalate-based Inorganic solids. Nat Chem 2009, 1:47-52.

21. Cooper G, Bouley A, Kitson P, Ritchie C, Richmond C, Thiel J, Gabb D, Eadie $R$, Long D-L, Cronin L: Osmotically driven crystal morphogenesis: a general approach to the fabrication of micrometer-scale tubular architectures based on polyoxometalates. J Am Chem Soc 2011, 133:5947-5954
22. Boulay A, Cooper G, Cronin L: Morphogenesis of polyoxometalate clusterbased materials to microtubular network architectures. Chem Commun 2012, 48:5088-5090.

23. Martin W, Boros J, Kelly D, Russell MJ: Hydrothermal vents and the origin of life. Nat Rev Microbiol 2008, 6:806-814.

24. Maselko J, Strizhak P: Spontaneous formation of cellular chemical system that sustains itself far from thermodynamic equilibrium. J Phys Chem 2004, 108:4937-4949.

25. Banzhaf W: Artificial Chemistries - toward constructive dynamical systems. Solida state. Phenomena 2004, 97/98:43-50.

26. Fontana W: Algorithmic Chemistry. In Artificial Life II, Edited by Langton C, Taylor C, Farmer D, Rasmussen St, Addison-Wesley, Reading MA 1992, 159-210.

27. Dittrick P, Ziegler J, Banzhaf W: Artificial Chemistries a review. Artif Life 2001, 7:22-75.

doi:10.1186/1759-2208-3-4

Cite this article as: Toth et al:: Pathway control in the self-construction of complex precipitation forms in a $\mathrm{Cu}(\mathrm{II})$-oxalate system. Journal of Systems Chemistry 2012 3:4

\section{Publish with ChemistryCentral and every scientist can read your work free of charge \\ “Open access provides opportunities to our colleagues in other parts of the globe, by allowing anyone to view the content free of charge."}

W. Jeffery Hurst, The Hershey Company.

- available free of charge to the entire scientific community

- peer reviewed and published immediately upon acceptance

- cited in PubMed and archived on PubMed Central

- yours - you keep the copyright

Submit your manuscript here:

http://www.chemistrycentral.com/manuscript/<smiles>c1ccccc1</smiles>

ChemistryCentral 